\title{
Genotipificación y resistencia antibacteriana de cepas de Campylobacter spp aisladas en niños y en aves de corral
}

\author{
Nancy Rivera F., Raúl Bustos B., Sonia Montenegro H., Marcelo Sandoval M., \\ Juan Castillo N., Heriberto Fernández J., Marcelo Maturana R., Lorena Delgado R., \\ Ángela Contreras S., Daniela Chávez N. e Iván Quevedo L.
}

\section{Genotyping and antibacterial resistance of Campylobacter spp strains isolated in children and in free range poultry}

Poultry is a main reservoir and source of human infection in campylobacteriosis. Three hundred and forty one stool samples (291 human, 50 avian) were analyzed. In the human group, 220 samples were collected from children with acute diarrheal disease (183 inpatients, 37 outpatients) and 71 from healthy children. Erythromycin and ciprofloxacin agar dilution MIC tests, Penner serotyping and RAPD-PCR genotyping were performed on 23 strains isolated. C. jejuni was reported only in patients with acute diarrhea (5.4\% inpatients, $2.2 \%$ outpatients). Campylobacter prevalence in poultry was 34\%. Cross-resistance to nalidixic acid and ciprofloxacin was found in $33.3 \%$ of human samples and $11.8 \%$ of animal samples. Human samples could not be typed using the Penner method. F serotype was the most expressed in poultry. We obtained a total of 14 genotypes (4 / 5 human and $10 / 15$ avian). In conclusion, the predominant species in poultry and humans was C. jejuni, a significant amount of quinolone-resistant human and avian samples were obtained, and avian genotypes and serotypes were not found in human samples. The latter would mean that another source of infection could exist; therefore other reservoirs must be studied.

Key words: Campylobacter spp., poultry, antibiotic susceptibility, MIC, RAPD-PCR, serotyping.

Palabras clave: Campylobacter spp., aves de corral, susceptibilidad in vitro, CIM, RAPD-PCR, serotipificación.

\section{Introducción}

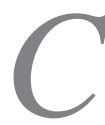
ampylobacter spp es uno de los patógenos intestinales más frecuentes, tanto en países desarrollados como en los que están en vías de desarrollo ${ }^{(1)}$. La campilobacteriosis es una enfermedad zoonótica que se adquiere tras la ingestión de comida o agua contaminada y leche $\sin$ pasteurizar ${ }^{2}$. Es de distribución mundial y afecta por igual a todas las razas, edades y sexos.

La especie más frecuente que causa infección en el hombre es Campylobacter jejuni subespecie jejuni, considerada como el primer agente de diarrea en el ser humano en los países desarrollados y el segundo o tercero en las naciones en vías de desarrollo ${ }^{3}$. Campylobacter jejuni se encuentra en el intestino de animales domésticos como aves, bovinos, ovinos y porcinos y se describe que $90 \%$ de las aves de corral son portadoras de Campylobacter spp, sin afectar su crecimiento . $^{4}$

Las aves de consumo y sus subproductos constituyen uno de los principales reservorios y fuente de infección humana ${ }^{5,6}$. La dosis infectante es de $10^{4}$ microorganismos, los cuales se multiplican en el intestino delgado, destru- yen la mucosa intestinal, invaden el epitelio y producen inflamación con infiltración de leucocitos en la lámina propia, pudiendo observarse la presencia de leucocitos en las heces en 25 a $80 \%$ de los casos.

En la infección por este género se han detectado enterotoxinas y toxinas citopáticas así como actividad citotóxica, aunque no está clara la participación de estos factores en el proceso de infección e invasión intestinal ${ }^{7}$. Teniendo en cuenta que la dosis infectante es baja, se entiende que los alimentos de origen animal son un riesgo apreciable de infección humana, por lo que se consideran actualmente zoonosis emergentes, de frecuencia creciente en todos los países ${ }^{2}$.

El conocimiento de las especies prevalentes, así como la individualización e identificación de las cepas aisladas proveen información epidemiológica y permite relacionar las fuentes de contagio y el modo de transmisión. Los métodos de tipificación convencionales, basados en pruebas bioquímicas, resistencia a varios agentes, tolerancia a diferentes temperaturas y serotipificación, son pruebas fenotípicas que se utilizan para caracterizar las cepas aisladas $^{8,9}$, existiendo también pruebas genotípicas que permiten hacer una mejor caracterización de las cepas ${ }^{10,11}$.
Universidad de

Concepción, Chile. Facultad de Medicina Departamento de Especialidades (NRF, SMH, JCN, ACS). Departamento de Pediatría (RBB, MMR).

Departamento de Medicina Interna (IQL).

Hospital Guillermo Grant Benavente, Concepción, Chile (MSM).

Universidad Austral de Chile, Valdivia, Chile (HFJ). Instituto de Salud Pública, Santiago, Chile (LDR).

Financiamiento: Proyecto DIUC No 206.083.024-1.0 Universidad de Concepción y Programa de Magíster en Ciencias Biomédicas Universidad de Talca.

Recibido: 10 de mayo de 2010 Aceptado: 4 de julio de 2011

Correspondencia a: Nancy Rivera F. nrivera@udec.cl 
En Chile, la notificación y derivación de Campylobacter spp. hacia los laboratorios de referencia, es baja, debido principalmente a que la mayoría de los laboratorios no estudian este agente por la falta de implementación de técnicas de diagnóstico. Esto a pesar que desde el año 1983, Campylobacter spp. es agente de vigilancia de laboratorio según lo establece el reglamento sobre notificación de enfermedades transmisibles de declaración obligatoria $\mathrm{N}^{\mathrm{o}} 712^{12}$. Por esto, no existen estadísticas oficiales de la prevalencia de campilobacteriosis.

La portación como reservorio de esta bacteria en las aves de consumo, genera uno de los eslabones epidemiológicos principales de contagio humano ${ }^{6}$.

Con respecto al tratamiento antimicrobiano de la campilobacteriosis cabe destacar que Campylobacter spp. es sensible a diversas clases de antimicrobianos, incluido macrólidos, especialmente eritromicina, y quinolonas como ciprofloxacina, siendo estos fármacos considerados de primera línea a la hora de aplicar el tratamiento clínico ${ }^{13}$. Hay trabajos científicos que consideran que la resistencia bacteriana a antimicrobianos se debe principalmente al excesivo uso de los mismos en seres humanos. Como asociación a esta situación, se plantea que el incremento de la resistencia de Campylobacter spp. a quinolonas en los reservorios animales puede conducir a fallos en el tratamiento de las diarreas producidas por estos microorganismos en el hombre. Para reducir la resistencia de Campylobacter spp. a fluoroquinolonas se ha recomendado no utilizar estos antimicrobianos en animales con fines profilácticos ${ }^{14}$.

Los estudios de susceptibilidad antimicrobiana a cepas de Campylobacter en el Instituto de Estandarización de Laboratorio Clínico (CLSI) ${ }^{26}$, han precisado los valores y condiciones de estudio según el método de CIM. Sin embargo, otros métodos como difusión en agar por disco, E-test ${ }^{\circledR}$ y difusión en disco, han dado resultados comparables y reproducibles ${ }^{2,15}$. Los resultados de estas investigaciones avalan la opción de utilizar la difusión por disco como método de test de susceptibilidad, siendo una técnica de fácil realización, lectura y menor complejidad. Además confirman la tendencia en otros estudios, de la creciente resistencia de las cepas de Campylobacter hacia las fluoroquinolonas ${ }^{13}$.

\section{Objetivo general}

Conocer aspectos genotípicos y epidemiológicos de Campylobacter spp en humanos y en aves de corral.

\section{Objetivos específicos}

- Determinar la especie predominante de Campylobacter spp. en aves de corral y comparar con datos previos obtenidos en humanos.

- Conocer la susceptibilidad antimicrobiana a eritromicina y ciprofloxacina de los aislados obtenidos, mediante difusión en agar y dilución en agar (CIM).
- Conocer el perfil genético de las cepas aisladas mediante RAPD-PCR y comparar con las cepas aisladas en humanos.

- Determinar los serotipos presentes en aislados de aves de corral y comparar con las cepas aisladas en humanos.

\section{Material y Método}

Período de estudio: Diciembre de 2006 a mayo de 2008.

Población humana: Se trabajó con muestras de deposición que llegaron al laboratorio de Microbiología del Hospital Guillermo Grant Benavente (HGGB) de Concepción, de pacientes con síndrome diarreico agudo (SDA), hospitalizados y ambulatorios, cuyo análisis se detalla y se procesaron también muestras de niños sanos.

Se analizaron las muestras de deposiciones obtenidas de 291 niños entre 0 y 14 años con SDA. De ellos, 183 se encontraban hospitalizados en el Servicio de Pediatría en el HGGB de Concepción y 37 niños con SDA fueron consultantes ambulatorios en el mismo hospital. Se incorporaron además 71 niños de control sano provenientes de un jardín infantil. A todos los padres se les solicitó el consentimiento informado.

Población aviar. Se obtuvo una muestra aleatoria simple de 50 aves de crianza doméstica de un mismo lugar de crianza en la provincia de Concepción.

Análisis de laboratorio. Las muestras de deposiciones se recolectaron en medio de transporte Cary Blair y se sembraron en placas de agar Brucella con sangre de caba11 o (5\%) y suplemento Skirrow, (vial de $2 \mathrm{cc}$ para $500 \mathrm{cc}$ de medio) conteniendo vancomicina 5,0 $\mu \mathrm{g}$, trimetoprim 2,5 $\mu \mathrm{g}$ y polimixina B 1.250 UI (Oxoid) (ASC) siendo derivadas al laboratorio de docencia de Tecnología Médica de la Universidad de Concepción para su incubación durante 48 horas y 72 horas, a $42^{\circ} \mathrm{C}$ bajo condiciones de microaerofilia, obtenida con sobres Campygen. Oxoid.

La sangre de caballo fue obtenida en forma aséptica con una Unidad Blosang ${ }^{\circledR}$ CPDA-1 Fenwal ${ }^{\circledR}$ solución anticoagulante citrato, fosfato, dextrosa y adenina.

La obtención de muestra en las aves, se hizo a través de hisopado cloacal con tórula, la que fue transportada al laboratorio docente de Tecnología Médica de la Universidad de Concepción, en medio Cary Blair en frío (unidad refrigerante) siendo trabajada en las mismas condiciones que las muestras humanas.

Análisis de colonias sospechosas. A las colonias sospechosas se les realizó tinción de Gram, prueba de 
catalasa y oxidasa, prueba de hidrólisis de hipurato, catalogando como C. jejuni todas las cepas que fueron hipurato positivo, para lo cual se usó un control positivo una cepa de Streptococcus agalactiae que también da esta prueba positiva y como Campylobacter coli aquellas cepas que no dieron positiva la prueba. Se guardaron las cepas puras en caldo glicerol, suero fisiológico $(\mathrm{NaCl}$ 9\%o) estéril, PBS, y Criobank.

Se realizó además una prueba de susceptibilidad a cefalotina y ác. nalidíxico por difusión en placa. Para esto se preparó una emulsión bacteriana en caldo Mueller Hinton $(\mathrm{CMH})$ ajustando la turbidez a un Mc Farland 1 , siendo diseminado en placa de agar Mueller Hinton sangre al 5\% (ASMH) por el método de Kirby Bauer utilizando discos de cefalotina y ác. nalidíxico (marca Oxoid), placas que fueron incubadas en microaerofilia a $42{ }^{\circ} \mathrm{C}$ por 48 hrs. Las especies de Campylobacter termófilo en estudio son resistentes a cefalotina y susceptibles a ác. nalidíxico, aunque en estas últimas se han observado cepas resistentes.

Las pruebas de susceptibilidad antimicrobiana se hicieron por medio de difusión en agar; para esto se realizó una emulsión en $\mathrm{CMH}$ ajustándose la turbidez a un Mc Farland 0,5 y con tórula fue diseminada de acuerdo a la técnica de Kirby Bauer en una placa ASMH las que fueron incubadas en microaerofilia a $42{ }^{\circ} \mathrm{C}$ por $48 \mathrm{hrs}$. Se utilizaron discos de eritromicina $15 \mu \mathrm{g}$ y ciprofloxacina $5 \mu \mathrm{g}$ (marca Oxoid). Los puntos de corte para la susceptibilidad por difusión en agar fueron obtenidos desde la literatura científica (Lucero y Turco ${ }^{16}$ ).

Para realizar la determinación de CIM se recuperaron las cepas desde caldo glicerol sembrándolas en ASC e incubándolas en microaerofilia a $42^{\circ} \mathrm{C}$ por $48 \mathrm{hrs}$. Luego de esto se realizó una emulsión en $\mathrm{CMH}$ ajustando la turbidez a un Mc Farland 0,5 según las recomendaciones de estandarización dada por la CLSI para CIM por dilución en agar.

Se prepararon placas con las siguientes diluciones para los antimicrobianos ya probados en la susceptibilidad por difusión en agar:

- Eritromicina: 0,03 $\mu \mathrm{g} / \mathrm{ml}$ - $16 \mu \mathrm{g} / \mathrm{ml}$.

- Ciprofloxacina: 0,004 $\mu \mathrm{g} / \mathrm{ml}-4 \mu \mathrm{g} / \mathrm{ml}$.

Se hicieron diluciones dobles seriadas de ambos antimicrobianos.

Las placas se prepararon con un volumen final de 22 $\mathrm{ml}$, de los cuales $20 \mathrm{ml}$ correspondieron a agar MüllerHinton; $1 \mathrm{ml}$ a sangre de caballo y $1 \mathrm{ml}$, al antimicrobiano diluido. En cada placa se sembraron inóculos de $1 \mu 1$. Para esto se usó un replicador MELROSE MACHINE SHOP 176. Se incubó en condiciones de microaerofilia durante 48 horas a $37^{\circ} \mathrm{C}$. Los puntos de corte para la susceptibilidad por CMI fueron obtenidos desde la literatura de los autores Lucero y Turco ${ }^{16}$.

\section{Estudio molecular de Campylobacter}

Para la extracción de ADN se utilizó una emulsión bacteriana, realizada en suero fisiológico estéril en el momento de la primera recuperación de la cepa, siendo guardadas a $-30{ }^{\circ} \mathrm{C}$ hasta su extracción. Esta extracción de ADN se realizó a cada una de las cepas, según el protocolo del kit Ultra Clean Microbial DNA Isolation ${ }^{\circledR}$ de MoBio Laboratorios, a través de un método enzimático. Se realizó RAPD a cada una de las muestras utilizando el primer OPA 5' CAA TCG CCG T 3' de Sygma Genosys. La master Mix de RPC es de $12 \mu$ conteniendo concentraciones finales de 2,5 $\mathrm{mM} \mathrm{MgCl}, 1 \mu \mathrm{M}$ de primer OPA11, $200 \mathrm{mM}$ de dNTPs (Promega) y 0,125 U de Taq-DNA polimerasa (Promega) $0,1 \mu \mathrm{l}$ de bovin albumin serum y $1 \mu \mathrm{l}$ de rojo cresol. Se agregó $5 \mu \mathrm{l}$ de ADN bacteriano. Se preparó un control negativo agregando $3 \mu \mathrm{l}$ de agua destilada en lugar de ADN. La amplificación por RPC se realizó en un termociclador Eppendorf Mastercycler Personal, un ciclo inicial de 3 minutos a $94{ }^{\circ} \mathrm{C}$, un ciclo de denaturación a $94{ }^{\circ} \mathrm{C}$ durante un minuto, un ciclo de hibridación a $36^{\circ} \mathrm{C}$ por un minuto y extensión a $72^{\circ} \mathrm{C}$ por dos minutos. Estos parámetros se repitieron durante 50 ciclos, se agregó una extensión final de $72{ }^{\circ} \mathrm{C}$ durante 10 minutos.

\section{Electroforesis}

Los productos de amplificación se corrieron en gel de agarosa al $2 \%$ con bromuro de etidio y se realizó la electroforesis durante una hora a 60-70 Volt, a temperatura ambiente, en tampónr TAE 1X. Se utilizó marcador de peso molecular de 100 bp Ladder. Posteriormente se hizo el análisis de las bandas obtenidas mediante comparación.

Para la serotipificación se recuperaron las cepas desde PBS sembrando en ASC e incubando por $48 \mathrm{hrs} \mathrm{a} 42{ }^{\circ} \mathrm{C}$ en microaerofília. Estas cepas de $C$. jejuni-coli fueron tipificadas utilizando antisueros comerciales (Denka Seiken, Japon) basados en el sistema de hemaglutinación pasiva propuesto por Penner $^{17}$ el cual incluye los siguientes serogrupos (25): A, B, C, D, E, F, G, I, J, K, L, N, O, P, $\mathrm{R}, \mathrm{S}, \mathrm{U}, \mathrm{V}, \mathrm{Y}, \mathrm{Z}, \mathrm{Z}_{2}, \mathrm{Z}_{4}, \mathrm{Z}_{5}, \mathrm{Z}_{6}, \mathrm{Z}_{7}$.

\section{Resultados}

Constatamos en este estudio que la prevalencia Campylobacter spp es significativamente mayor en las aves de corral en comparación con las muestras de deposiciones humanas (Tabla 1). Incluso si se considera la suma de la prevalencia de Campylobater spp. en los controles sanos, los pacientes hospitalizados por SDA y los pacientes tratados en forma ambulatoria por SDA (Tabla 2). Respecto a la prevalencia de las especies de Campylobacter, nuestro estudio evidenció que Campylobacter coli no se encontró en las muestras humanas (Tabla 3 ).

Respecto a la susceptibilidad antimicrobiana de las cepas por disposición en agar y CIM se puede observar 
Tabla 1. Prevalencia de Campylobacter spp. en humanos y en aves de corral

\begin{tabular}{lccc} 
Procedencia de las muestras & Muestras analizadas & \multicolumn{2}{c}{ Muestras positivas } \\
& $\mathrm{n}$ & $\mathrm{n}$ & $\%$ \\
\hline Humana & 291 & 6 & 2,1 \\
Aves de corral de crianza casera & 50 & 17 & 34 \\
\hline
\end{tabular}

Tabla 2. Prevalencia de Campylobacter spp. según condición clínica de los pacientes

\begin{tabular}{lccc} 
Procedencia & Muestras analizadas & \multicolumn{2}{c}{ Muestras positivas } \\
& $\mathrm{n}$ & $\mathrm{n}$ & $\%$ \\
\hline SDA ambulatorios & 37 & 2 & 5,4 \\
SDA hospitalizados & 183 & 4 & 2,2 \\
Control sano & 71 & 0 & 0,0 \\
\hline Total & 291 & 6 & 2,06 \\
\hline
\end{tabular}

Tabla 3. Prevalencia de Campylobacter spp. según especie en las dos poblaciones de estudio: aves de corral crianza doméstica y muestras humanas

\begin{tabular}{|lcccccc|}
\hline Especie & \multicolumn{2}{c}{ Aves de corral } & \multicolumn{2}{c}{ Muestras humanas } & \multicolumn{2}{c|}{ Total } \\
& $\mathrm{n}$ & $\%$ & $\mathrm{n}$ & $\%$ & $\mathrm{n}$ & $\%$ \\
\hline C. jejuni & 13 & 77 & 6 & 100 & 19 & 83 \\
\hline C. coli & 4 & 23 & 0 & 0 & 4 & 17 \\
\hline Total & 17 & 100 & 6 & 100 & 23 & 100 \\
\hline
\end{tabular}

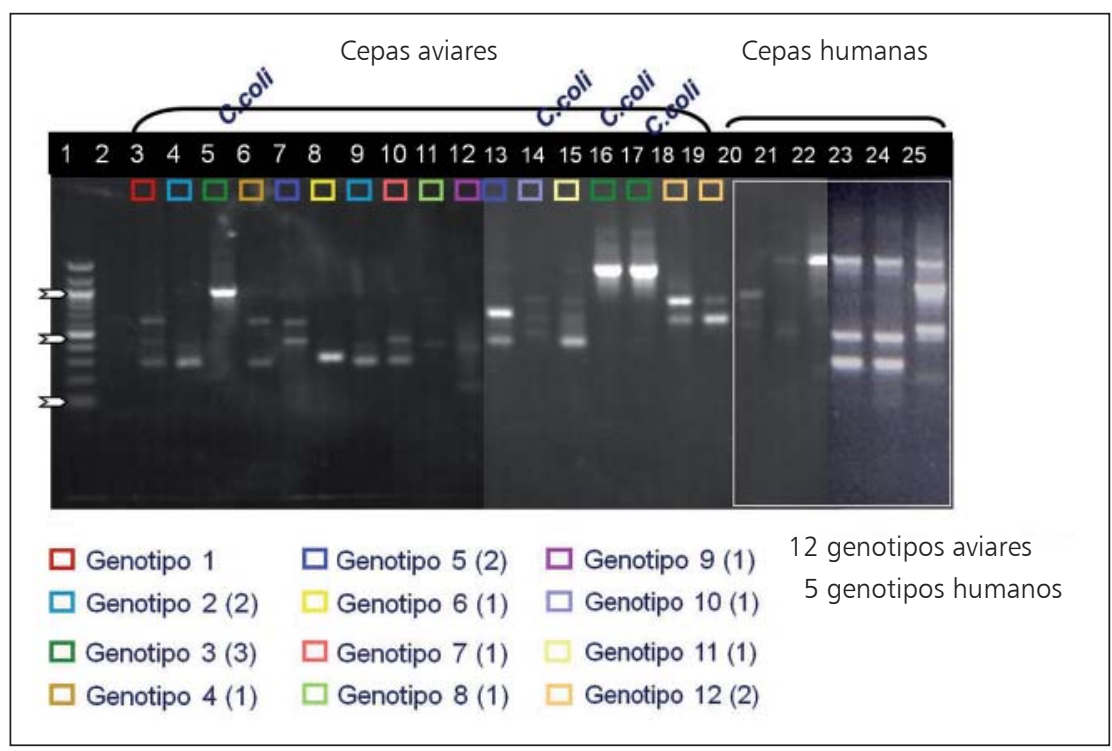

Figura 1. RAPD-PCR de cepas de Campylobacter spp. aisladas desde muestras de origen aviar y humano. Las flechas del costado izquierdo de la Figura 1, de abajo hacia arriba indican 100 pb, $500 \mathrm{pb}$ y $1.500 \mathrm{pb}$, correspondiente al marcador de peso molecular del carril 1. que las cepas de C. jejuni aisladas desde humanos fueron, en su totalidad, susceptible a eritromicina por el método de difusión en placa y por CIM. La misma situación pudo observarse en los aislados desde aves de corral, donde no se encontró cepas resistentes a eritromicina. En cambio, al realizar estudios de susceptibilidad para ciprofloxacina en las cepas aisladas en humanos, 33,3\% $(\mathrm{n}=6)$ presentó resistencia a este antimicrobiano con halos de $6 \mathrm{~mm}$ y CIM $\geq 4 \mu \mathrm{g} / \mathrm{ml}$. Ello se repitió en las cepas aisladas desde aves de corral, donde se encontró $11,8 \%$ de resistencia a ciprofloxacina, con halos de $6 \mathrm{~mm}$ por difusión y CIM de $4 \mu \mathrm{g} /$ $\mathrm{ml}$. Es necesario hacer notar que la resistencia observada fue en las cepas 26 y 39, siendo ambas C. coli (Tabla 4).

En definitiva, no se encontró cepas resistentes a eritromicina. Hubo resistencia cruzada a ác. nalidíxico y ciprofloxacina. Las cepas humanas presentaron 33,3\% de resistencia a ciprofloxacina y en las cepas provenientes de aves fue sólo de 11,8\%.

Respecto a la serotipificación de algunas de las cepas animales (por agotamiento de reactivos), y en la totalidad de las cepas humanas se observó que las cepas humanas fueron no tipificables por el método de Penner. Las cepas aviares (8/17) aglutinaron con más de un antisuero de Penner siendo prevalente el serotipo F (Tabla 5).

En el estudio preliminar de Campylobater a través de RAPD-PCR se observó que las cepas animales (n: 17) presentaron 12 genotipos RAPD y las cepas humanas (n: 6) presentaron cinco genotipos RAPD. Se puede apreciar también que dos cepas aviares presentan idéntico genotipo (carril 16 y 17), así también dos cepas humanas (carril 23 y 24) (Figura 1).

\section{Discusión}

De acuerdo a los resultados obtenidos, se confirma una alta prevalencia de Campylobacter spp. en muestras de deposición de origen aviar, 34\%, cifra que es un poco mayor a lo informado por Fernández y cols, en el año 2000. Al respecto se debe hacer notar que las aves muestreadas en el presente estudio, fueron todas de crianza doméstica por no encontrar apoyo en avícolas de producción regional. Aunque existe un trabajo reciente en Chile (año 2011), éste no informa prevalencia de Campylobacter en aves, sino sólo porcentaje de resistencia a ciprofloxacina en los aislados encontrados ${ }^{18}$. Con respecto a las muestras humanas analizadas en Concepción, destaca el hecho de no encontrar cepas de C. coli y una baja prevalencia de Campylobacter como género. Si comparamos estos datos con los obtenidos en el único trabajo realizado años atrás en Concepción en pacientes hospitalizados, Henríquez y cols, $1985^{27}$ se obtuvo una prevalencia un poco mayor a lo informado por estos autores, $1,7 \%$ versus $2,7 \%$. En cuanto a especie se confirma la presencia de C. jejuni, en este caso como única especie encontrada. 
Con respecto a la alta prevalencia de Campylobacter spp. en las muestras aviares se puede inferir de acuerdo a los datos proporcionados por la encuesta aplicada a la dueña de las aves, que la fuente de contagio entre las aves para la portación de la bacteria es propia de los hábitos de las aves, como la coprofagia, por ejemplo, pues la crianza de estas es efectuada en un recinto cerrado, exclusivo para ellas sin contacto con otro tipos de animales domésticos como los perros en los cuales también se describe la presencia de Campylobacter; además, el agua consumida por las aves sometidas al estudio era de tipo potable y la alimentación de estas se realizaba en recipientes.

Los resultados obtenidos en el estudio de susceptibilidad antimicrobiana fueron concordantes con los publicados anteriormente por otros autores, donde se señala la creciente resistencia in vitro de Campylobacter a quinolonas. Entre los estudios realizados en animales, específicamente en aves de corral, se describen resultados similares a los obtenidos en este trabajo. Es el caso de Hariharan y cols., el año $2008^{19}$ que comunica una resistencia a ciprofloxacina de $12,5 \%$ similar al $11,7 \%$ detectado en las cepas aisladas en este trabajo. En otros estudios se reporta mayor cantidad de cepas resistentes alcanzando a $48,8 \%$ de resistencia a quinolonas en $C$. coli (Cardinale y cols., año 2006) ${ }^{20}$, datos que hacen aumentar la preocupación por las condiciones de crianza y vigilancia veterinaria de las aves de corral. En la presente investigación, si bien existe resistencia a ciprofloxacina, ésta no es tan elevada $(11,8 \%)$ ya que las aves en estudio, por ser de crianza casera, no tienen control periódico con veterinario y sólo se solicita su presencia en caso de enfermedad, no conociéndose el uso de antimicrobianos en ellas, según datos proporcionados por los criadores. González G. y cols., en el año 2011, en Chile, obtuvieron $27 \%$ de resistencia a ciprofloxacina en cepas de C. jejuni de origen aviar, no especificando si las aves eran de crianza doméstica o industrial ${ }^{18}$. Este es un factor que en la literatura científica se considera importante en el creciente aumento de genes de resistencia en Campylobacter spp. aislado desde animales ${ }^{20}$. La literatura médica describe también la baja resistencia a macrólidos como eritromicina $^{24}$; sin embargo, en nuestro estudio no se encontraron cepas resistentes a este antimicrobiano.

El porcentaje de resistencia de C. jejuni a ciprofloxacina fue de $33,3 \%$ sin encontrarse resistencia a eritromicina, similar a lo encontrado por otros investigadores chilenos, González G., año 2011, en aislados de C. jejuni de origen humano $(32 \%)^{18}$.

Gaudreau y cols., año $2007^{21}$, también compararon ambos métodos de estudio de susceptibilidad antimicrobiana utilizados en nuestro trabajo, con resultados similares y la excelente correlación existente entre CIM y difusión en placa, lo que determina que cualquiera de los dos métodos es válido para realizar estudios de susceptibilidad
Tabla 4. Susceptibilidad antimicrobiana de las cepas de Campylobacter por difusión en agar y CIM

\begin{tabular}{|c|c|c|c|c|c|}
\hline \multirow[t]{2}{*}{ Cepas } & \multirow[t]{2}{*}{ Origen } & \multicolumn{2}{|c|}{ Difusión en agar } & \multicolumn{2}{|c|}{$\mathrm{CIM} \mathbf{m g} / \mathrm{ml}$} \\
\hline & & Eritromicina & Ciprofloxacina & Eritromicina & Ciprofloxacina \\
\hline 5 & Animal & S & S & $0,25(\mathrm{~S})$ & $0,625(\mathrm{~S})$ \\
\hline 11 & $"$ & S & S & $0,125(S)$ & $0,031(S)$ \\
\hline 26 & $"$ & S & $R$ & $0,25(\mathrm{~S})$ & $4(\mathrm{R})$ \\
\hline 27 & $"$ & S & S & $0,25(\mathrm{~S})$ & $0,031(S)$ \\
\hline 29 & $"$ & S & S & $0,125(S)$ & $0,06(\mathrm{~S})$ \\
\hline 30 & $"$ & S & S & $0,125(S)$ & $0,031(S)$ \\
\hline 31 & $"$ & S & S & $0,25(\mathrm{~S})$ & $0,031(S)$ \\
\hline 32 & $"$ & $S$ & $S$ & $0,25(S)$ & $0,031(S)$ \\
\hline 33 & $"$ & $S$ & S & $0,5(S)$ & $0,06(\mathrm{~S})$ \\
\hline 34 & $"$ & S & S & $0,25(S)$ & $0,625(S)$ \\
\hline 35 & $"$ & S & S & $0,25(S)$ & $0,125(S)$ \\
\hline 36 & $"$ & S & S & $0,5(S)$ & $0,06(S)$ \\
\hline 38 & $"$ & S & S & $0,5(S)$ & $0,031(S)$ \\
\hline 39 & $"$ & S & $R$ & $0,25(S)$ & $4(R)$ \\
\hline 42 & $"$ & S & S & $0,5(S)$ & $0,125(S)$ \\
\hline 43 & $"$ & S & S & $0,25(S)$ & $0,031(S)$ \\
\hline 50 & $"$ & S & S & $0,125(S)$ & $0,06(\mathrm{~S})$ \\
\hline 359 & Humano & S & S & $0,25(S)$ & $0,25(\mathrm{~S})$ \\
\hline 787 & $"$ & S & $R$ & $1(\mathrm{~S})$ & $4(\mathrm{R})$ \\
\hline 889 & $"$ & S & S & $0,25(\mathrm{~S})$ & $1(S)$ \\
\hline 16 & $"$ & S & S & $0,25(\mathrm{~S})$ & $0,125(S)$ \\
\hline 77 & $"$ & S & $R$ & $0,25(S)$ & $>4(\mathrm{R})$ \\
\hline 118 & $"$ & S & S & $0,25(\mathrm{~S})$ & $0,125(\mathrm{~S})$ \\
\hline
\end{tabular}

Tabla 5. Serotipos de Campylobacter spp en cepas de origen aviar $y$ origen humano

\begin{tabular}{|ccl|}
$\begin{array}{c}\text { Procedencia aviar } \\
\text { n cepa }\end{array}$ & Especie & Serotipos \\
\hline 5 & C. jejuni & F, Y, Z5 \\
11 & C. jejuni & F \\
26 & C. coli & F, V, Z7 \\
27 & C. jejuni & Z4, Z5, Z6 \\
\hline 29 & C. jejuni & F, Z5, Z6 \\
30 & C. jejuni & F, Z7 \\
\hline 31 & C. jejuni & A, F, O, Z6 \\
\hline 32 & C. jejuni & Autoaglutinación \\
\hline Procedencia humana & \\
n cepa & Especie & Serotipos \\
\hline 359 & C. jejuni & No tipificable \\
\hline 787 & C. jejuni & No tipificable \\
\hline 889 & C. jejuni & No tipificable \\
16 & C. jejuni & No tipificable \\
\hline 77 & C. jejuni & No tipificable \\
\hline 118 & C. jejuni & No tipificable \\
\hline
\end{tabular}


en Campylobacter. Esto fue ratificado por Rivera y cols., en Concepción el año 200722, quien obtuvo los mismos resultados por ambos métodos.

Entre las cepas en estudio, tanto humanas como aviares, se encontró resistencia cruzada a ác. nalidíxico en todas aquellas que mostraron resistencia a ciprofloxacina, lo que se podría explicar por la presencia de una mutación descrita por Boonmar y cols., en el año $2007^{23}$. Esta corresponde a una mutación puntual en Thr 86 donde hay un cambio por Ile86, a diferencia de otras mutaciones descritas para la resistencia adquirida a ciprofloxacina en Asp60 o Ala90. Ello indica la baja efectividad de la determinación de susceptibilidad a ác. nalidíxico como prueba de identificación de especie, ya que existirían cepas de $C$. jejuni y $C$. coli resistentes a este antimicrobiano; en este estudio la prueba definitoria de especie fue la prueba de hidrólisis de hipurato de sodio.

Del total de cepas aisladas (n: 17), sólo se serotipificó 8 de ellas obteniéndose aglutinación con más de un serogrupo en 7 cepas, posiblemente debido a que la producción de antisueros se realiza con sueros no adsorbidos. Una de las cepas no pudo ser serotipificada ya que presentó auto-aglutinación. Los serotipos predominantes en los aislados aviares fueron F, Z5 y Z6; en cambio Fernández y cols., $2005^{24}$ reportan que los serotipos predominantes en aves fueron A, C, L e Y aunque también encontraron el serotipo F pero en una sola cepa. Los serotipos que este estudio encuentran en animales, Fernández los encuentra en humanos, resultados que se podrían explicar por el hecho de tratarse de muestras de distinto origen geográfico y además por tratarse de aves de distinta crianza, una casera y otra industrial. Es necesario hacer notar que la muestra de aves analizada correspondió a un criadero de tipo casero, por lo tanto, la comercialización de las aves no llega a la población y el consumo de ellas es mayoritariamente familiar y sólo se comercializan los huevos. Lo anteriormente expresado podría explicar la diferencia en cuanto a los serotipos encontrados en la población humana. Sería apropiado estudiar cepas provenientes de aves de crianza industrial que mayormente llega a la población. El hecho de que se muestren serotipos diferentes en los aislados sugiere que pueda existir otra fuente de contagio de Campylobacter spp. para los humanos, aparte del consumo de carne de ave. En el estudio realizado recientemente en Concepción, con muestras humanas sólo se sometió a serotipificación tres de las seis cepas, las cuales fueron no tipificables por el método de Penner, ya que el kit proporciona sólo 25 antisueros, los más prevalentes en Europa, y no necesariamente presente en nuestra región geográfica, no siendo posible establecer comparaciones. Tampoco hay antecedentes previos en la zona acerca de los serotipos de Campylobacter circulantes que apoyen nuestros resultados.

De acuerdo al RAPD-PCR, de 20 cepas, 15 de origen animal y 5 de origen humano, se obtuvo 13 genotipos RAPD. De animales hubo nueve genotipos con predominio del genotipo 2 el cual corresponde a tres cepas de $C$. jejuni y tres cepas de $C$. coli. Estos resultados muestran, por una parte amplia variabilidad genética entre las cepas y por otra, que puede existir flujo genético entre las especies ya que se encontraron dos cepas de $C$. coli que presentan el mismo genotipo de C. jejuni. Pero también puede ocurrir que las cepas identificadas como C. coli, fuesen $C$. jejuni hipurato negativo y para dilucidar esto habría que hacer otras pruebas de identificación tanto fenotípicas, como genotípicas. Esto se observó con otras cepas que están en el carril 9 y 12 siendo una $C$. jejuni y la otra C. coli. El año 2006, Acik y cols. ${ }^{25}$, hallaron gran variabilidad genética en aislados de origen animal de $C$. jejuni y C. coli, obteniendo 87 genotipos RAPD de 348 aislados. Se observan diferencias entre los genotipos de las cepas provenientes de animales con respecto a las cepas humanas lo que nos está indicando diferencias en la clonalidad de las cepas. Para identificar totalmente dicha clonalidad sería necesario fabricar una matriz primaria y luego usar un programa computacional que nos indique la clonalidad de las cepas.

En conclusión, nuestro trabajo permitió determinar que la especie predominante en aves de corral fue C. jejuni al igual que lo encontrado en humanos, que las cepas de origen aviar fueron $100 \%$ susceptibles a eritromicina al igual que las cepas humanas de Concepción, tanto mediante difusión en agar como por dilución (CIM), que las cepas de origen animal presentaron 11,7\% de resistencia, tanto a ác. nalidíxico como a ciprofloxacina y para las cepas humanas este valor fue de $33,3 \%$, lo que nos indica que hay un mayor porcentaje de cepas resistentes a ciprofloxacina entre las cepas humanas. Cabe hacer notar que dada la baja prevalencia de Campylobacter spp., en las muestras analizadas, el estudio de susceptibilidad fue hecho con muy pocas cepas, no obstante sigue la tendencia internacional ${ }^{23,24}$.

Se debe tener presente el aumento de la resistencia a quinolonas y la resistencia cruzada que se produce a la hora de usar la prueba de susceptibilidad a ác. nalidixico como recurso para la identificación de las especies de Campylobacter. La cantidad de genotipos obtenidos mediante RAPD-PCR para cepas humanas y animales confirma la variabilidad genética de Campylobacter spp. Las cepas de procedencia humana no aglutinaron con alguno de los serogrupos, lo que indica que corresponden a distintos serotipos no incluidos en el kit de serotipificación. No se encuentra relación entre las cepas que circulan entre las aves y las humanas, tanto desde el punto de vista fenotípico como desde el punto genotípico. Esto nos hace inferir que la fuente de contagio puede ser otra, sin descartar el que puedan ser aves de corral, pero de otra procedencia como es la industrial. 
Agradecimientos. A la Srta. Q.F. Fanny Arenas, por todo el apoyo en la parte molecular de este trabajo, a la Sra. Magda Hernández y Sra. Teresa Castillo, personal auxiliar del laboratorio de docencia de Tecnología Médica por todo el apoyo logístico de esta Investigación y al Médico Veterinario, Lisandro Muñoz quien, hizo posible contar con sangre equina para la elaboración de placas para medio de cultivo.

\section{Resumen}

Las aves de consumo constituyen uno de los principales reservorios y fuente de infección humana de la campilobacteriosis. Se analizaron 341 muestras de deposiciones, 291 humanas y 50 aviares. De las muestras, 220 de niños con síndrome diarreico agudo-SDA (183 hospitalizados y 37 consultantes ambulatorios) y 71 niños sanos. A las
23 cepas obtenidas se les realizó CIM por dilución en agar a eritromicina y ciprofloxacina, serotipificación de Penner y genotipificación por RAPD-PCR. Se encontró Campylobacter jejuni sólo en pacientes con SDA, de ellos $5,4 \%$ ambulatorios y 2,2\% hospitalizados. En aves, la prevalencia de Campylobacter spp., fue de 34\%. Hubo resistencia cruzada a ácido nalidixico y ciprofloxacina en $33,3 \%$ cepas de origen humano y $11,8 \%$ animal. Las cepas humanas fueron no tipificables por el método de Penner. Predominó entre las aves el serotipo F. Se obtuvo un total de 14 genotipos (4/5 humanos y 10/15 aviares). En conclusión, la especie predominante en aves de corral y en humanos fue C. jejuni, existiendo una alta prevalencia de cepas de origen humano y aviar resistentes a quinolonas. Los genotipos y serotipos aviares no fueron encontrados en cepas de origen humano, lo que indica que podría existir otra fuente de infección, por lo que se requiere estudiar otros reservorios.

\section{Referencias}

1.- Fernández H, Farace M. Manual de procedimientos; diagnóstico de Campylobacter en muestras clínicas y de alimentos. Universidad Austral de Chile e Instituto Nacional de Enfermedades Infecciosas Argentina. 2003.

2.- Cáceres M. Campylobacter, un inquietante desafío; XLII Simposio Científico de Avicultura. 2005 Pág. 101-6. (accedido: 12 de marzo de 2008).

3.- Murray P, Baro E, Jorgensen J, Landry M, Pfaller M. Manual of Clinical Microbiology. $9^{a}$. Ed. Washington, D.C.: American Society for Microbiology 2007: 933-41

4.- Farnell M B, Donoghue A M, Cole K, Reyes-Herrera I, Blore P J, Donoghue D I. Campylobacter susceptibility to ciprofloxacin and corresponding fluoroquinolone concentrations within the gastrointestinal tracts of chickens.

J Appl Microbiol 2005; 99: 1043-50.

5.- Fernández H, Torres N. Campylobacter jejuni y Campylobacter coli en tres grupos de gallinas de diferente origen geográfico del sur de Chile. Arch Med Vet 2000; 32: 241-4.

6.- Murray P Rosenthal, K Pfaller. Microbiología Médica. $5^{\mathrm{a}}$ edición .2006: 347-51.

7.- Campos M, Herrera M, Vargas A, Herrera J. Bacteremia por Campylobacter spp en un paciente con agamaglobulinemia ligada al cromosoma X (XLA): primer caso reportado en Costa Rica. Rev Méd Hosp Nac Niños (Costa Rica) 2000; 35: 59-66.

8.- Washington C, Winn Jr W C, Allen S D, Janda W M, Koneman E W, Procop G, et al. Koneman's Color Atlas and Textbook of Diagnostic Microbiology. $6^{\mathrm{a}}$ edición, 2006:
393-407.

9.- Giacoboni G, Puchuri MC, Castellano C. Echeverría G, Fernández H. Identificación mediante biotipos y perfiles proteicos de Campylobacter aislados de perros. Arch Med Vet Valdivia 1999; 31 (2): 231-5

10.- Açik M, Çetinkaya B. Random amplified polymorphic DNA analysis of Campylobacter jejuni and Campylobacter coli isolated from healthy cattle and sheep. J Med Microbiol 2006; 55: 331-4.

11.- Debruyne L, Samyn E, De Brandt E, Vandenberg O, Heyndrickx M, Vandamme P. Comparative performance of different PCR assays for identification of Campylobacter jejuni and Campylobacter coli. Res Microbiol 2008; 159: 88-93.

12.- Manual de vigilancia de Laboratorio de Campylobacter spp. Descripción Técnica de Vigilancia de Laboratorio de Campylobacter spp según decreto $N^{o}$ 158/2004 del Ministerio de Salud. www.ispch.cl, (accedido 20 de abril 2008).

13.- Senok A, Yousif A, Mazi W, Sharaf E, Bindayna K, Elnima E, et al. Pattern of antibiotic susceptibility in Campylobacter jejuni isolates of human and poultry origin. Japan J Infect Dis 2007; 60: 1-4.

14.- Orden J, De la Fuente R. Implications on public health of quinolone resistance in bacteria of animal origin. Rev Esp Salud Pública, Madrid, 2001; 75, (4).

15.- Engberg J, Aarestrup F, Taylor D, Gerner-Smidt P, Nachamkin I. Quinolone and macrolide resistance in Campylobacter jejuni and C. coli: Resistance mechanisms and trends in human isolates. Emerg Infect Dis 2001; 7 (1): 24-34.
16.- Lucero C, Turco M. Diagnóstico microbiológico de infección gastrointestinal por Campylobacter spp. Servicio antimicrobianos INEI - ANLIS Dr Carlos G. Malbran. http:// www.aam.org.ar/actividades/Campylobacter. pdf.

17.- Penner J L, Hennessy J N. Passive hemagglutination technique for serotyping Campylobacter fetus subsp. jejuni on the basis of soluble, heat-stable antigens. J Clin Microbiol 1980; 12 (6): 732-7.

18.- González G, Troncoso M, Figueroa G. Biotipos y antibiogramas de aislados de Campylobacter jejuni de origen aviar, bovino y humano. Libro de resúmenes de X Jornadas Científicas, Instituto de Salud Pública de Chile. 2011: 57.

19.- Hariharan H, Sharma S, Chikweto A, Matthew V, DeAllie C. Antimicrobial drug resistance as determined by the E-test in Campylobacter jejuni, C. coli, and C. lari isolates from the ceca of broiler and layer chickens in Grenada. Comp Immunol Microbiol Infect Dis 2008; 32 (1): 21-8.

20.- Cardinale E, Rose V, Perrier Gros-Claude J D, Tall F, Rivoal K, Mead G, et al. Genetic characterization and antibiotic resistance of Campylobacter spp. isolated from poultry and humans in Senegal. J Appl Microbiol 2006; 100 (1): 209-17.

21.- Gaudreau Ch, Girouard Y, Ringuette L, Tsimiklis C. Comparison of disk diffusion and agar dilution methods for erythromycin and ciprofloxacin susceptibility testing of Campylobacter jejuni subsp. jejuni Antimicrob Agents Chemother 2007; 51: 1524-6.

22.- Rivera N, Fernández H, Bustos R, Valenzuela M, Trabal N, Montenegro S. Susceptibilidad 
antimicrobiana de cepas de Campylobacter aisladas de carcasas de aves, sangre y fecas humanas. Revlab 2007; 1: 32-7.

23.- Boonmar S, Morita Y, Fijuita M, Sangsuk L, Suthivarakom K, Padungtod P, et al.

Serotypes, antimicrobial susceptibility, and gyr a genes mutation of Campylobacter jejuni isolates from humans and chickens in Thailand. Microbiol Inmunol 2007; 51 (5): 531-7.
24.- Fernández H, García A, Villanueva M P. Serotipos de Campylobacter jejuni ssp. jejuni aislado en carne de ave para consumo humano y en muestras de heces de niños con diarrea. Arch Med Vet 2005; 37 (1): 79-81.

25.- Acik M, Cetinkaya B. Random amplified polimorphic DNA analysis of Campylobacter jejuni and Campylobacter coli isolated from healthy cattle and sheep. J Med Microbiol 2006;
55: 331-4.

26.- Clinical and Laboratory Standards Institute/ CLSI. Performance standards for antimicrobial susceptibility testing. Fifteenth Informational Supplement CLSI/CLSI document M100 S15. Clinical and Laboratory Standards Institute 2005; $25: 168$.

27.- Henríquez M, Venegas G, Soto G, Rudolff T, Salas J. Etiología bacteriana de la diarrea aguda del lactante en otoño e invierno. Rev Chil Pediatr 1985; 56 (6): 450-3. 